\title{
Les dimensions spatiales et sociales des églises évangéliques et pentecôtistes en banlieue parisienne et sur l'île de Montréal
}

Frédéric Dejean

\section{(2) OpenEdition}

Journals

Édition électronique

URL : http://journals.openedition.org/cdg/2863

DOI : $10.4000 /$ cdg. 2863

ISSN : 2107-7266

Éditeur

UMR 245 - CESSMA

Référence électronique

Frédéric Dejean, «Les dimensions spatiales et sociales des églises évangéliques et pentecôtistes en banlieue parisienne et sur l'île de Montréal », Carnets de géographes [En ligne], 2 | 2011, mis en ligne le 02 mars 2011, consulté le 07 mai 2019. URL : http://journals.openedition.org/cdg/2863 ; DOI :

$10.4000 /$ cdg. 2863

Ce document a été généré automatiquement le 7 mai 2019.

\section{(c) $(1) \Theta \Theta$}

La revue Carnets de géographes est mise à disposition selon les termes de la Licence Creative Commons Attribution - Pas d'Utilisation Commerciale - Pas de Modification 4.0 International. 


\title{
Les dimensions spatiales et sociales des églises évangéliques et pentecôtistes en banlieue parisienne et sur l'île de Montréal
}

\author{
Frédéric Dejean
}

\section{Une approche géographique des communautés évangéliques et pentecôtistes dans les espaces urbains}

1 S'il existe une géographie du tourisme, des transports, ou de la santé, il n'existe pas de véritable géographie du fait religieux de langue française, alors même que ce que l'on désigne parfois comme un « retour du religieux » se joue en grande partie dans l'espace. Que l'on pense seulement aux nombreux débats en France sur la construction de lieux de culte musulmans ou sur le port du voile : dans les deux cas les enjeux sont éminemment spatiaux.

2 Cet intérêt pour la géographie du fait religieux est en continuité avec mes expériences de recherche antérieure: un mémoire de maitrise (Paris I-Sorbonne, sous la direction de Jacques Brun) portant sur la visibilité du religieux dans la ville, à partir de l'exemple de la mosquée Adda'wa, située dans le $19^{\text {àme }}$ arrondissement de Paris, suivi d'un Master 2 conduit à l'ENS Lyon et à Paris VIII, sous la direction de Hervé Vieillard-Baron. Ce Master 2 m'a permis de me familiariser avec les communautés évangéliques et pentecôtistes, objets de ma recherche doctorale.

3 Le questionnement de départ de ce travail de thèse était relativement simple : si le fait religieux s'est adapté aux différentes mutations sociales, ce dont rendent compte les sociologues, le travail du géographe est alors de comprendre comment le fait religieux s'adapte aux mutations récentes de l'espace, notamment dans les villes. Si ces dernières 
ne sont pas que de simples décors pour les faits sociaux, on peut penser qu'elles changent le religieux, de même que le religieux peut les changer.

4 Ce questionnement général sur le fait religieux dans les espaces urbains contemporains a été affiné du fait même de l'objet de recherche: les communautés évangéliques et pentecôtistes, et notamment des communautés issues de l'immigration. Dans le paysage religieux français, ces communautés connaissent une croissance réelle, ce qui est d'autant plus remarquable dans un contexte de baisse de la pratique religieuse et une emprise moindre des grandes institutions sur leurs membres.

5 La perspective géographique sur ces communautés m'a conduit à interroger leurs dimensions spatiales. L'ensemble de la recherche a été sous-tendue par l'idée que la spatialité originale et parfois déroutante de ces communautés (en particulier la localisation des lieux de culte dans des hangars, des ateliers, des bureaux...) témoigne de leur importante capacité d'adaptation aux réalités urbains contemporaines et à proposer ainsi de nouveaux modes de visibilité du fait religieux dans les espaces urbains. Par ailleurs, j'ai essayé de montrer que les lieux de culte ne s'inscrivent pas tant dans des territoires locaux, mais sont insérés dans des logiques réticulaires, fonctionnant aussi bien à l'échelle de la métropole qu'à l'échelle internationale.

\section{La pratique du double terrain}

6 Le terrain d'investigation fut double puisque mon ambition était de mener une comparaison. Celle-ci a permis de faire ressortir des points communs et des différences entre des communautés similaires, en fonction des contextes socio-spatiaux dans lesquels elles étaient insérées. Le premier terrain fut la commune de Saint-Denis, en Seine SaintDenis, département caractérisé par sa concentration de communautés évangéliques et pentecôtistes, en particulier celles issues de l'immigration d'Afrique sub-saharienne et du bassin caribéen. Le second terrain retenu fut deux arrondissements (Rosemont et Villeray/Saint-Michel/Parc Extension) de la métropole montréalaise. Si les modèles urbains parisien et montréalais sont différents, ces deux arrondissements possèdent des points communs avec Saint-Denis du point de vue de la morphologie urbaine. Concernant plus spécifiquement mon objet de recherche, le choix de ces deux espaces était pertinent dans la mesure où des responsables religieux sont passés par la France avant de gagner le Québec et que les liens entre les communautés québécoises et françaises sont particulièrement forts.

7 Afin de conduire au mieux cette recherche l'approche qualitative a principalement été retenue. Celle-ci fut partagée en deux versants: une observation participante qui m'a permis d'entrer en contact avec les communautés et des entretiens avec des acteurs privilégiés (pasteurs, responsables d'associations ou d'organisations religieuses, élus). A ceci s'est ajouté ce que j'ai appelé des " marches exploratoires », consistant à recueillir un matériel photographique des lieux de culte de manière à en établir une typologie en fonction de leur visibilité dans l'espace urbain. Une dimension plus quantitative, néanmoins modeste, a été donnée au travail de recherche, par le biais de questionnaires d'enquêtes distribués aux fidèles, principalement au cours des cultes du dimanche matin.

Fiche informative 
Discipline

Géographie (France), Etudes urbaines (Québec)

\section{Directeurs}

Annick Germain (INRS-UCS, Montréal) et Hervé Vieillard-Baron (Université de Paris Ouest Nanterre-La Défense)

\section{Universités}

INRS-UCS (Montréal) et Paris Ouest Nanterre-La Défense

Membres du jury de thèse, soutenue le 21 novembre 2010

- Marie-Hélène Bacqué, Université de Paris Ouest-Nanterre-La Défense

- Elisabeth Dorier-Apprill, rapporteur, Université de Provence

- Sébastien Fath, CNRS

- Annick Germain, directrice, INRS-UCS

- David Hanna, rapporteur, Université du Québec à Montréal

- Pierre J. Hamel, INRS-UCS

- Hervé Vieillars-Baron, directeur, Université de Paris Ouest-Nanterre-La Défense

Situation professionnelle actuelle

Détaché de l'Education Nationale, post doctorant à l'Université de Montréal

Contact de l'auteur

Frederic.dejean@yahoo.fr

INDEX

Thèmes : Carnets de soutenances 